\title{
The Association Between Fear of Falling and Orthostatic Hypotension in Older Adults
}

\author{
Ferhat Arik ${ }^{\mathrm{a}}$, Pinar Soysal ${ }^{\mathrm{b}}$, Emre Capar $^{\mathrm{c}}$, , Ugur Kalan $^{\mathrm{d}}$ \\ Lee Smith ${ }^{\mathrm{e}}$, Mike Trott ${ }^{\mathrm{f}}$, Ahmet Turan Isik ${ }^{\mathrm{g}}$
}

a Department of Internal Medicine, Tomarza Yasar Karayel State Hospital, Kayseri, Turkey

${ }^{b}$ Department of Geriatric Medicine, Bezmialem Vakif University, Faculty of Medicine, Istanbul, Turkey.

${ }^{\mathrm{c}}$ Department of Internal Medicine, Marmara University, Istanbul, Turkey

d. Department of Internal Medicine, Ermenek State Hospital, Karaman, Turkey..

${ }^{\mathrm{e}}$ Cambridge Centre for Sport and Exercise Sciences, Anglia Ruskin University, Cambridge, UK.

${ }^{\mathrm{f}}$ Cambridge Centre for Sport and Exercise Sciences, Anglia Ruskin University, Compass House, Cambridge, CB1 1PT, UK

${ }^{\mathrm{g}}$ Department of Geriatric Medicine, Faculty of Medicine, Dokuz Eylul University, Izmir, Turkey

Correspondig author: Pinar Soysal, MD

Department of Geriatric Medicine, Bezmialem Vakif University, Faculty of Medicine, Istanbul, Turkey.

Email: dr.pinarsoysal@hotmail.com 


\title{
The Association Between Fear of Falling and Orthostatic Hypotension in Older Adults
}

\begin{abstract}
:
The aim of this study was to determine the relationship between fear of falling/the degree of fear of falling (FoF) and orthostatic hypotension $(\mathrm{OH})$ in older adults. This cross-sectional study was conducted with 314 older outpatients. If the total score of the Falls Efficacy Scale-International scale was 16-19, 20-27 and $\geq 28$, it was assumed that there was low FoF, moderate FoF, and high FoF, respectively. OH was evaluated for the 1st $(\mathrm{OH} 1)$ and 3rd $(\mathrm{OH} 3)$ minutes, after transitioning from the supine position to standing. Participants were aged 65 to 93 years (mean age $74.2 \pm 8.5$ years) and 193 (61.5\%) were female. Among FoF groups, significant differences were found for age, gender, education, marital status, who the patient lived with, the history of falling and hypertension, Timed Up-Go test score, and hemoglobin levels $(\mathrm{p}<0.005)$. The prevalence of $\mathrm{OH} 1$ and $\mathrm{OH} 3$ were found to be significantly higher in those with a FoF score of 20 and above than those below 20 ( $\mathrm{p}<0.005)$. After adjustment for potential confounders, participants who reported a high FoF had higher risk for $\mathrm{OH} 1$ and $\mathrm{OH} 3$ (OR: 2.14, 95\% CI: 1.14-4.0, p=0.017; and OR:2.72, 95\% CI:1.46-5.09, $\mathrm{p}=0.002$, respectively), but those with moderate FoF had no increased risk of having $\mathrm{OH}$ compared to low FoF ( $>0.05$ ). There is a close relationship between high FoF and $\mathrm{OH}$ in older adults. Therefore, when evaluating an older patient with $\mathrm{OH}$, FoF should be evaluated, or FoF should also be questioned in older patients with $\mathrm{OH}$.
\end{abstract}

Keywords: Fear of falling, orthostatic hypotension, older 


\section{INTRODUCTION}

Orthostatic hypotension $(\mathrm{OH})$ is common in older adults and its prevalence varies between $20 \%$ and $40 \%$ depending on the evaluation method or the time elapsed after standing up from the lying position (1). Insufficiency in arterial baroreflex sensitivity, and a decrease in renin-angiotensin aldosterone level as well as its sensitivity may aid in the development of $\mathrm{OH}$ in older people (2). However, neurodegenerative diseases such as parkinson's disease, diabetes mellitus, malnutrition, frailty, dehydration, or drugs used (such as antihypertensive drugs, levodopa, antidepressants and benzodiazepines), which increase with aging, further increases the possibility of this condition (3-6). For these reasons, negative clinical problems associated with $\mathrm{OH}$ are more commonly in older people.

In an umbrella review compiling all the latest published observational studies, $\mathrm{OH}$ was found to be associated with falling, coronary heart disease, congestive heart failure, stroke, dementia, and all-cause mortality (7). OH may result in decreased physical activity and decreased functionality owing to associated symptoms when being active such as dizziness, blackouts, temporary loss of consciousness, weakness, nausea and drowsiness $(8,9)$. Therefore, patients may develop fear of being mobilized owing to fear of falling (FoF), that may consequently increase risk of repeated falls over time. However, although the studies carried out so far have shown the relationship of $\mathrm{OH}$ with falling, it is not known whether FoF, which is as important as falls in geriatric practice, is associated with $\mathrm{OH}(10)$.

The aim of this study was to determine the relationship between FoF/the degree of FoF and the 1st and 3rd minutes of $\mathrm{OH}$ in older people.

\section{METHODS}

\subsection{Participants}

This cross-sectional study was conducted with 314 adult participants aged 65 years and over, who were referred to one geriaric clinic in Turkey between August 2018 and March 2019. Inclusion criteria included: aged 65 years and over, applying to the clinic for any health reason and the ability to understand and answer questions. Patients who refused to participate, participants diagnosed with dementia or unable to complete FoF questionnaires, patients with serious illnesses that may impair the general health condition such as acute cerebrovascular accident, sepsis, acute renal failure, acute coronary syndrome and acute respiratory failure were excluded from the study. Patients' age, gender, level of education, concurrent systemic and chronic 
diseases, and number of medications used were recorded. During admission patients were asked whether they had fallen in the previous year and the previous month. History of hypertension, coronary artery disease, congestive heart failure, diabetes mellitus, hyperlipidemia, peripheral arterial disease, chronic obstructive pulmonary disease, osteoporosis, thyroid disease, and cerebrovascular disease were determined by patients' self-report.

\subsection{The Falls Efficacy Scale - International (FES-I) (11)}

FES-I was used to determine and classify FoF. The scale consists of 16 questions and 1-4 points are assigned to each question. FoF was classified according to the total score given to the questions. Total FES-I scores range from minimum 16 (no concern about falling) to maximum 64 (severe concern about falling). In addition, if the total score of the FES-I scale was 16-19, 20-27 and $\geq 28$, it was assumed that there was low FoF, moderate FoF, and high FoF, respectively. Timed Up and Go test (TUG) were also used for evaluation gait and balance function.

\subsection{Orthostatic Hypotension (OH) (1)}

Blood pressure of patients was measured in the supine position and after standing up for the diagnosis of $\mathrm{OH}$. Blood pressure measurements were carried out in an environment away from noise and temperature in accordance with the correct measurement rules. The patients were informed about avoiding exercise and not eating or drinking (caffeinated beverages such as coffee, tea, cola, cigarettes) 30 minutes before there appointment. Moreover, the patient then waited for 30 minutes before measurements were taken. Blood pressure was measured in the supine position, and after the patient stood up, and recorded at the 1st and 3rd minutes. For the measurement of blood pressure, a calibrated Omron M2 Compact (HEM 7102-E) device that meets the requirements of the international protocol was used. $\mathrm{OH}$ was defined as a decrease in systolic and / or diastolic blood pressure $\geq 20 \mathrm{mmHg}$ and / or $\geq 10 \mathrm{mmHg}$, respectively, when an individual moved from the supine position to the upright position. For example, the diagnosis of $\mathrm{OH}$ in the $1^{\text {st }}$ min was made by the presence of systolic $\mathrm{OH}$ in the $1^{\text {st }} \mathrm{min}$ and/or diastolic $\mathrm{OH}$ in the $1^{\text {st }}$ min.

\subsection{Laboratory findings}

To evaluate the biochemical relationship of FoF and the metabolic condition, blood samples were collected in the morning after at least 8 hours of fasting. Venous blood samples were drawn into a standard biochemical tube for biochemical assay from all patients. Complete blood count, kidney, liver and trioid function tests, electrolytes, Vitamin D was recorded. 


\subsection{Statistical Analysis}

Histogram, q-q graphs and Shapiro-Wilk test were used to evaluate data normality. Levene test was performed to evaluate variance homogeneity. To compare the differences among groups, independent samples $t$ test, one-way analysis of variance (ANOVA) and Kruskal-Wallis tests were used for continuous variables, while Pearson chi-square analysis were used for categorical variables. For post-hoc comparisons, Tukey, Tamhane T2, Dunn-Bonferroni and Bonferroni-adjusted z test were applied. Relationships between FoF groups and $\mathrm{OH}$ groups were investigated using multiple binary regression models adjusted for all potential confounders including age, gender, education, marital status, living arrangement, history of falls, diabetes, cardiovascular disease, hypertension, TUG time scores, hemoglobin level and Vitamin D deficiency. All statistical analyses were performed using the Statistical Package for the Social Sciences 22.0 (SPSS Inc.). P values below 0.05 were considered statistically significant. The required number of samples was calculated as at least 276 patients, with an acceptable 5\% error and 95\% confidence level.

\section{RESULTS}

A total of 314 participants were included in the study aged 65 to 93 years (mean age $74.2 \pm 8.5$ years), and $193(61.5 \%)$ were female. Of the 314 older adults admitted to the clinic, 30.6\%, 29.6\% and 39.8\% were in the low FoF, moderate FoF and high FoF groups, respectively. $\mathrm{OH}$ was examined at 1 and 3 minutes after standing up, and the prevalence of $\mathrm{OH} 1$ and $\mathrm{OH} 3$ was $20.3 \%$ and $21 \%$ in the study population, respectively. In patients with high FoF, the prevalence of $\mathrm{OH} 1$ and $\mathrm{OH} 3$ was $28 \%$ and $31.2 \%$, respectively. The comparison of patients characteristics according to FoF's groups is summarized in Table 1. Among these groups, significant differences were found for age, gender, education, marital status, who the patient lived with, the history of falling in the past year and last month, TUG test scores, hemoglobin level and hypertension $(\mathrm{p}<0.005)$.

Table 1. Comparison of demographic data, laboratory results and orthostatic blood pressure changes with fear of falling groups obtained from FES-I scores 


\begin{tabular}{|c|c|c|c|c|c|}
\hline & & \multicolumn{3}{|c|}{ FES-I SCORES } & \multirow[b]{2}{*}{$p$} \\
\hline & & $\begin{array}{c}16-19 \\
(n=96)\end{array}$ & $\begin{array}{l}20-27 \\
(n=93)\end{array}$ & $\begin{array}{c}\geq 28 \\
(n=125)\end{array}$ & \\
\hline Age & year & $71.57 \pm 5.97$ & $72.81 \pm 6.18$ & $74.13 \pm 7.14$ & 0.016 \\
\hline \multirow{2}{*}{ Sex } & Female & $45(23.2)$ & $63(32.6)$ & $85(44.0)$ & \multirow{2}{*}{0.002} \\
\hline & Male & $51(42.1)$ & $30(24.8)$ & $40(68)$ & \\
\hline \multirow{3}{*}{$\begin{array}{l}\text { Education } \\
\text { (years) }\end{array}$} & none & $33(23.6)$ & $51(36.4)$ & $56(40)$ & \multirow{3}{*}{0.027} \\
\hline & $1-5$ & $52(26)$ & $37(24.7)$ & $61(40.7)$ & \\
\hline & 5 -over & $8(38.1)$ & $4(19)$ & $6(28.6)$ & \\
\hline \multirow{2}{*}{ Marital status } & Married & $79(33.7)$ & $77(32.9)$ & $78(33.3)$ & \multirow{2}{*}{$<0.001$} \\
\hline & Widowed & $17(21.2)$ & $16(20.0)$ & $47(58.7)$ & \\
\hline \multirow{2}{*}{$\begin{array}{l}\text { Living } \\
\text { arrangement }\end{array}$} & Alone & $16(28.5)$ & $13(23.1)$ & $27(48.2)$ & \multirow{2}{*}{$<0.001$} \\
\hline & Spouse & $80(31.0)$ & $80(31.0)$ & $98(38.0)$ & \\
\hline \multirow{2}{*}{$\begin{array}{l}\text { Falling (last } \\
\text { year) }\end{array}$} & Yes & $9(16.9)$ & $14(26.4)$ & $30(56.6)$ & \multirow{2}{*}{0.014} \\
\hline & No & $87(33.3)$ & $79(30.3)$ & $95(36.4)$ & \\
\hline \multirow{2}{*}{$\begin{array}{l}\text { Falling (last } \\
\text { month) }\end{array}$} & Yes & $3(15)$ & $2(10)$ & $15(75)$ & \multirow{2}{*}{0.004} \\
\hline & No & 93 (31.6) & $91(31)$ & $110(37.4)$ & \\
\hline \multirow{2}{*}{ Polypharmacy } & Yes & $15(35.7)$ & $14(33.3)$ & $13(31)$ & \multirow{2}{*}{0.449} \\
\hline & No & $81(29.7)$ & $79(29)$ & $112(41.2)$ & \\
\hline \multirow{2}{*}{ DM } & Yes & $38(39.1)$ & $26(26.8)$ & $33(34)$ & \multirow{2}{*}{0.084} \\
\hline & No & $58(26.7)$ & $67(30.9)$ & $92(42.4)$ & \\
\hline \multirow{2}{*}{$\begin{array}{l}\text { Cardiovascular } \\
\text { disease }\end{array}$} & Yes & $11(20)$ & $14(25.5)$ & $30(54.5)$ & \multirow{2}{*}{0.078} \\
\hline & No & $85(32.8)$ & $79(30.5)$ & $95(36.7)$ & \\
\hline \multirow{2}{*}{ HT } & Yes & $50(24.3)$ & $63(30.7)$ & $92(44.9)$ & \multirow{2}{*}{0.003} \\
\hline & No & $46(42.2)$ & $30(27.5)$ & $33(30.2)$ & \\
\hline \multirow{2}{*}{$\begin{array}{l}\text { Depressive } \\
\text { symptoms }\end{array}$} & Yes & $8(25.8)$ & $9(29)$ & $14(45.2)$ & \multirow[b]{2}{*}{0.776} \\
\hline & No & $88(31.1)$ & $84(29.7)$ & $111(39.2)$ & \\
\hline TUG (3 meter) & & $10(7-20)$ & $11(7-22)$ & $14(0-44)$ & $<0.001$ \\
\hline \multicolumn{6}{|c|}{ Laboratory findings } \\
\hline Glucose & $\mathrm{mg} / \mathrm{dL}$ & $120(102-158)$ & $113(100-138)$ & $109(100-133)$ & 0.153 \\
\hline Hemoglobin & $\mathrm{g} / \mathrm{dL}$ & $14.78 \pm 1.56$ & $13.95 \pm 1.60$ & $13.35 \pm 1.56$ & $<0.001$ \\
\hline TSH & $\mathrm{mg} / \mathrm{dL}$ & $1.26(0.80-2.28)$ & $1.06(0.69-1.89)$ & $1.16(0.69-1.86)$ & 0.516 \\
\hline \multirow{2}{*}{$\begin{array}{l}\text { Deficiency of } \\
\text { Vitamin D }\end{array}$} & Yes & $71(28.6)$ & $77(31)$ & $100(40.3)$ & \multirow[t]{2}{*}{0.308} \\
\hline & No & $25(37.8)$ & $16(24.2)$ & $25(37.9)$ & \\
\hline
\end{tabular}

Orthostatic Blood Pressure Changes 


\begin{tabular}{|c|c|c|c|c|c|}
\hline \multirow{2}{*}{$\begin{array}{l}\text { Systolic OH } \\
\text { (first minute) }\end{array}$} & Yes & $2(7.1)$ & $10(35.7)$ & $16(57.1)$ & \multirow[t]{2}{*}{0.016} \\
\hline & No & $94(32.8)$ & $83(29)$ & $109(38.1)$ & \\
\hline \multirow{2}{*}{$\begin{array}{l}\text { Diastolic OH } \\
\text { (first minute) }\end{array}$} & Yes & $8(20)$ & $13(32.5)$ & $19(47.5)$ & \multirow{2}{*}{0.289} \\
\hline & No & $88(32.1)$ & $80(29.2)$ & $106(38.7)$ & \\
\hline \multirow{2}{*}{$\begin{array}{l}\text { OH } \\
\text { (first minute) }\end{array}$} & Yes & $9(14)$ & $20(31.3)$ & $35(54.7)$ & \multirow{2}{*}{0.008} \\
\hline & No & $87(34.8)$ & $73(29.2)$ & $90(36)$ & \\
\hline \multirow{2}{*}{$\begin{array}{l}\text { Systolic OH } \\
\text { (third minute) }\end{array}$} & Yes & $5(12.8)$ & $11(28.2)$ & $23(59)$ & \multirow{2}{*}{0.013} \\
\hline & No & $91(23.6)$ & $82(29.8)$ & $102(37.1)$ & \\
\hline \multirow{2}{*}{$\begin{array}{l}\text { Diastolic OH } \\
\text { (third minute) }\end{array}$} & Yes & $4(10)$ & $13(32.5)$ & $23(57.5)$ & \multirow{2}{*}{0.006} \\
\hline & No & $92(33.6)$ & $80(29.2)$ & $102(37.2)$ & \\
\hline \multirow{2}{*}{$\begin{array}{l}\text { OH } \\
\text { (third minute) }\end{array}$} & Yes & $8(12.1)$ & $19(28.8)$ & $39(59.1)$ & \multirow{2}{*}{$<0.001$} \\
\hline & No & $88(45.5)$ & $74(29.8)$ & $86(34.7)$ & \\
\hline
\end{tabular}

DM: diabetes mellitus; HT: Hypertension; OH: orthostatic hypotension; TSH: thyroid-stimulating hormone; TUG: Timed Up and Go. The data is expressed using N (\%). mean \pm standard deviation or median at first and third quarter.

The prevalence of $\mathrm{OH} 1$, systolic $\mathrm{OH} 1$, and $\mathrm{OH} 3$, systolic and diastolic $\mathrm{OH} 3$ were found to be significantly higher in those with a FoF score of 20 and above than those below $20(\mathrm{p}<0.005)$.

According to those with low FoF (FES-1 score 16-19), the risk of $\mathrm{OH}$ in the moderate FoF and high FoF groups is shown in table 2. Participants who reported a high FoF had higher risk for $\mathrm{OH} 1$ and $\mathrm{OH} 3$ (OR:2.14, 95\% CI:1.14-4.0, p=0.017; OR:2.72, 95\% CI:1.46-5.09, p=0.002, respectively), after adjustment for all potential confounders including age, gender, education, marital status, living arrangement, history of falls, diabetes, cardiovascular disease, hypertension, TUG time scores, hemoglobin level and Vitamin D deficiency. However, after adjustment for the same confounders, those with moderate FoF had no increased risk of having $\mathrm{OH}$ compared to low FoF ( $\mathrm{p}>0.05)$.

Table 2. The Association Between Fear of Falling And Orthostatic Hypotension 


\begin{tabular}{|l|l|c|l|c|}
\hline & \multicolumn{3}{|c|}{$\begin{array}{c}\mathbf{2 0 - 2 7} \\
\text { (n:93) }\end{array}$} & \multicolumn{1}{|c|}{$\begin{array}{c}\text { FES-I SCORES } \\
\text { (n:125) }\end{array}$} \\
\cline { 2 - 5 } & \multicolumn{1}{|c|}{ OR (95\% CI) } & $p$ & OR (95\% CI) & $p$ \\
\hline $\begin{array}{l}\text { Systolic OH } \\
\text { (first minute) }\end{array}$ & $1,20(0,51-2,81)$ & 0,670 & $2,58(1,07-6,24)$ & 0,035 \\
\hline $\begin{array}{l}\text { Diastolic OH } \\
\text { (first minute) }\end{array}$ & $1,30(0,61-2,74)$ & 0,488 & $1,22(0,57-2,60)$ & 0,599 \\
\hline $\begin{array}{l}\text { OH } \\
\text { (first minute) }\end{array}$ & $1,10(0,59-2,06)$ & 0,747 & $2,14(1,14-4,00)$ & 0,017 \\
\hline $\begin{array}{l}\text { Systolic OH } \\
\text { (third minute) }\end{array}$ & $0,79(0,36-1,71)$ & 0,55 & $2,69(1,26-5,77)$ & 0,011 \\
\hline $\begin{array}{l}\text { Diastolic OH } \\
\text { (third minute) }\end{array}$ & $1,16(0,54-2,45)$ & 0,69 & $1,98(0,93-4,49)$ & 0,073 \\
\hline $\begin{array}{l}\text { OH } \\
\text { (third minute) }\end{array}$ & $0,89(0,47-1,67)$ & 0,727 & $2,72(1,46-5,09)$ & 0,002 \\
\hline
\end{tabular}

$\mathrm{OH}$ : orthostatic hypotension, Logistic regression analysis. (OR: odds ratio, CI: confidence Interval)

It was determined that there was a significant relationship between 7 items of FoF and 1 minute $\mathrm{OH}$, and 14 items of FoF with 3 minutes $\mathrm{OH}(\mathrm{p}<0.005)$. Supplementary table 1 shows which items of FoF are related to $\mathrm{OH}$ in the 1st and 3rd Minute. The presence of $\mathrm{OH}$ according to scores from each FES-1 questions were also shown in this table.

\section{DISCUSSION}

In this study, it was observed that moderate and high FoF is common in the elderly $(30 \%$ and $40 \%$, respectively). It was found that there was a higher FoF in women, those living alone, living with relatives or caregivers, those with a history of falling in the past month or in the past year, and with hypertension. It was observed that advanced age, low hemoglobin and prolonged TUG test were associated with increased FoF. Moreover, it was observed that the $\mathrm{OH}$ prevalence of the first and third minutes increased as FoF from low to high grade increased.

FoF may be an important correlate for the development of disability in older adults (12) The prevalence of FoF is $20-39 \%$ among older adults (12-14). In the present study, the percentage of participants who stated that they had low FoF, moderate FoF and high FoF was 30.6\%, 29.6\% and 39.8\%, respectively. The reason for these high ratios may be owing to differences in populations studied (community-dwelling older adults versus outpatients). On the other hand, studies conducted in health institutions have been shown to be as high as the present study $(15,16)$. These results underscore the importance of evaluating FoF in older adults 
who are admitted to the hospital with any health problems. The finding that FoF is seen more frequently in older women than men, is compatible with sevral previous studies. Indeed, older women compared to older men are more likely to avoid activity due to pain. Moreover, decrease in muscle strength or musculoskeletal problems such as degenerative arthritis are more common in older women than older men $(13,17)$. This may result in over-fear of falling among older women. In those who live alone, if they fall, maybe not being able to get up for an extended period of time, or the absence of anyone to lift them off the ground, may cause a heightend FoF. On the other hand, FoF may be high in people living with relatives or caregivers, as they may be affected by their functional capacity to live alone at home. The relationship between prolonged TUG test and increased FoF supports this hypothesis.

Both $\mathrm{OH}$ and FoF have many common adverse outcomes such as cognitive impairment, functional impairments, depression, and poor quality of life in the older adults (18). However, the number of studies investigating the relationship between these two situations is very limited. In this study, it was found that there was a positive correlation between the presence of $\mathrm{FoF}$ and $\mathrm{OH}$, and also, $\mathrm{OH}$ was more frequent, especially in those who described high FoF. Since the present study is cross-sectional the direction of the association is not known that is whether FoF leads to $\mathrm{OH}$ or whether $\mathrm{OH}$ leads to FoF. Nevertheless, some possible mechanisms can explain this relationship. Depending on $\mathrm{OH}$; recurrent falls and problems with gait and balance in older adults can lead to decreased functionality, thus resulting in physical inactivity and consequently may contribute to the development of FoF. OH causes sudden reduction in brain perfusion and oxygenation within a few minutes of postural change; this may result in symptoms such as dizziness, postural lightheadedness, vertigo, and blurred vision in those with $\mathrm{OH}(9)$. On the other hand, $\mathrm{OH}$ causes impaired muscle microcirculation and pain in the neck, hip and calf muscles (19). At the same time, chronic brain pathology, such as brain atrophy, microbleeds and white matter brain lesions are more common in those with $\mathrm{OH}$; which might influence the perception of verticality, resulting in positive dizziness. All these reasons can explain how $\mathrm{OH}$ can cause FoF.

FOF has been identified as an independent risk factor for reduced quality of life, activity restriction, loss of independence, and fall-risk; a leading cause of injury, morbidity, and mortality (20). As a result, those who have FoF, begin to limit their daily activities in order not to fall again, and consequently, there may be a decrease in muscle strength and balance abilities. The reduced muscle mass and muscle strength can lead to a reduction in effective venous return, since venous pumps in the leg muscles pump blood from the lower extremity to the heart, which is important in maintaining cardiac filling pressure (21). For example, Suzuki et al., in their study of young subjects, reported that there was a decrease in venous return and cardiac output following 20-day bed rest, due to the decrease in muscle mass and muscle strength, and that patients had 
deterioration in orthostatic tolerance capacity (22). Accordingly, FoF can be a risk factor for $\mathrm{OH}$ in older adults.

The present study has several strengths blood pressure measurements and the data of all other tests were collected by one physician. Moreover, OH-related studies are generally performed using single measurement, blood pressure measurements for $\mathrm{OH}$ in this study were carried out over 1-3 minutes. Measurements were performed using a device that calibrates automatically and by this way, physcian error has been minimized. The most important limitation of the study is its cross-sectional nature. Thus, further longitudinal studies are now required for the determination of causality. Another limitation may be that $\mathrm{OH}$ was not measured utilizing the Head-up-Tilt table test.

\section{CONCLUSION}

$\mathrm{OH}$ and FoF are two major geriatric syndromes that are closely related. Moreover, the higher the severity of FoF, the stronger the association between FoF and $\mathrm{OH}$ is. Therefore, when evaluating an older adult with FoF in geriatric practice, $\mathrm{OH}$ should also be evaluated and vice versa. Thus, more effective management of the two will be possible and common complications due to both may be reduced.

Conflict of interest statement: The authors report no conflict of interest.

Funding sources: The study has no funding.

Ethical Statement: The study design and all procedures performed in studies involving human participants were in accordance with the ethical standards of the institutional and/or national research committee (Ethics Committee of Erciyes University Health Application and Research Center Hospital 2017/544) and with the 1964 Helsinki Declaration and its later amendments or comparable ethical standards.

Human and animal rights disclosure: This article does not contain any studies with animals performed by any of the authors. Informed consent Informed consent was obtained from all individual participants included in the study 


\section{References}

1. Aydin AE, Soysal P, Isik AT. Which is preferable for orthostatic hypotension diagnosis in older adults: Active standing test or head-up tilt table test? Clin Interv Aging. 2017;12.

2. Robertson D. The pathophysiology and diagnosis of orthostatic hypotension. Clin Auton Res. 2008 Mar;18 Suppl 1:2-7.

3. Soysal P, Aydin AE, Koc Okudur S, Isik AT. When should orthostatic blood pressure changes be evaluated in elderly: 1st, 3rd or 5th minute? Arch Gerontol Geriatr. 2016;65.

4. Isik AT, Kocyigit SE, Smith L, Aydin AE, Soysal P. A comparison of the prevalence of orthostatic hypotension between older patients with Alzheimer's Disease, Lewy body dementia, and without dementia. Exp Gerontol. 2019 Sep;124:110628.

5. Kocyigit SE, Soysal P, Bulut EA, Aydin AE, Dokuzlar O, Isik AT. What is the relationship between frailty and orthostatic hypotension in older adults? J Geriatr Cardiol. 2019 Mar;16(3):272-9.

6. Kocyigit SE, Soysal P, Ates Bulut E, Isik AT. Malnutrition and Malnutrition Risk Can Be Associated with Systolic Orthostatic Hypotension in Older Adults. J Nutr Heal Aging. 2018;

7. P. S, N. V, L. S, G. T, S.E. J, L. Y, et al. Orthostatic hypotension and health outcomes: an umbrella review of observational studies. Eur Geriatr Med [Internet]. 2019;10(6):863-70. Available from: http://www.epistemonikos.org/documents/e4335d82b71d411c635fa6b4e744056a825f1a56

8. Mol A, Reijnierse EM, Bui Hoang PTS, van Wezel RJA, Meskers CGM, Maier AB. Orthostatic hypotension and physical functioning in older adults: A systematic review and meta-analysis. Ageing Res Rev. 2018 Dec;48:122-44.

9. Low PA, Opfer-Gehrking TL, McPhee BR, Fealey RD, Benarroch EE, Willner CL, et al. Prospective evaluation of clinical characteristics of orthostatic hypotension. Mayo Clin Proc. 1995 Jul;70(7):617-22.

10. Mol A, Bui Hoang PTS, Sharmin S, Reijnierse EM, van Wezel RJA, Meskers CGM, et al. Orthostatic Hypotension and Falls in Older Adults: A Systematic Review and Meta-analysis. J Am Med Dir Assoc. 2019 May;20(5):589-597.e5.

11. Delbaere K, Close JCT, Mikolaizak AS, Sachdev PS, Brodaty H, Lord SR. The Falls Efficacy Scale International (FES-I). A comprehensive longitudinal validation study. Age Ageing. 2010 Mar;39(2):210-6.

12. Whipple MO, Hamel A V, Talley KMC. Fear of falling among community-dwelling older adults: A scoping review to identify effective evidence-based interventions. Geriatr Nurs. 2018 Mar;39(2):170-7. 
13. Tomita Y, Arima K, Tsujimoto R, Kawashiri S-Y, Nishimura T, Mizukami S, et al. Prevalence of fear of falling and associated factors among Japanese community-dwelling older adults. Medicine (Baltimore). 2018 Jan;97(4):e9721.

14. Rivasi G, Kenny RA, Ungar A, Romero-Ortuno R. Predictors of Incident Fear of Falling in Community-Dwelling Older Adults. J Am Med Dir Assoc. 2019 Oct;

15. Turhan Damar H, Bilik O, Karayurt O, Ursavas FE. Factors related to older patients' fear of falling during the first mobilization after total knee replacement and total hip replacement. Geriatr Nurs. 2018 Jul;39(4):382-7.

16. van Seben R, Reichardt LA, Aarden JJ, van der Schaaf M, van der Esch M, Engelbert RHH, et al. The Course of Geriatric Syndromes in Acutely Hospitalized Older Adults: The Hospital-ADL Study. J Am Med Dir Assoc. 2019 Feb;20(2):152-158.e2.

17. Lim E. Sex Differences in Fear of Falling among Older Adults with Low Grip Strength. Iran J Public Health. 2016 May;45(5):569-77.

18. Lach HW, Parsons JL. Impact of fear of falling in long term care: an integrative review. J Am Med Dir Assoc. 2013 Aug;14(8):573-7.

19. Bleasdale-Barr KM, Mathias CJ. Neck and other muscle pains in autonomic failure: their association with orthostatic hypotension. J R Soc Med. 1998 Jul;91(7):355-9.

20. Young WR, Mark Williams A. How fear of falling can increase fall-risk in older adults: applying psychological theory to practical observations. Gait Posture. 2015 Jan;41(1):7-12.

21. Rowel LB. Human Cardiovascular Control. 1th ed. UK: Oxford University Press; 1993.

22. Suzuki Y, Murakami T, Kawakubo K, Haruna Y, Takenaka K, Goto S, et al. Regional changes in muscle mass and strength following 20 days of bed rest, and the effects on orthostatic tolerance capacity in young subjects. J gravitational Physiol a J Int Soc Gravitational Physiol. 1994 May;1(1):P57-8.

\section{Supplementary Table 1}




\begin{tabular}{|c|c|c|c|c|c|c|c|c|}
\hline \multicolumn{9}{|c|}{$\begin{array}{l}\text { Supplementary table 1. } 1 \text { st and 3rd minute } \mathrm{OH} \text { findings according to scores from each } \\
\text { FES-1 questions }\end{array}$} \\
\hline & & & & & & & & \\
\hline & & & & \begin{tabular}{c}
\multicolumn{1}{c}{1} \\
Not at all \\
concerned
\end{tabular} & $\begin{array}{c}2 \\
\text { Somewhat } \\
\text { concerned }\end{array}$ & $\begin{array}{c}3 \\
\text { Fairly } \\
\text { concerned }\end{array}$ & $\begin{array}{c}4 \\
\text { Very } \\
\text { concerned }\end{array}$ & P value \\
\hline & \multirow{4}{*}{$\begin{array}{l}\text { Cleaning the house (e.g. } \\
\text { sweep. vacuum or dust) }\end{array}$} & \multirow{2}{*}{$\mathrm{OH} 1$} & Yes & $31(48.4)$ & $19(29.7)$ & $9(14.1)$ & $5(7.8)$ & \multirow{2}{*}{0.025} \\
\hline 1 & & & No & $164(65.6)$ & $48(19.2)$ & $32(12.8)$ & $6(2.4)$ & \\
\hline 1 & & \multirow{2}{*}{$\mathrm{OH} 3$} & Yes & $27(40.9)$ & $21(31.8)$ & $13(19.7)$ & $5(7.6)$ & \multirow{2}{*}{0.001} \\
\hline & & & No & $168(67.7)$ & $46(18.5)$ & $28(11.3)$ & $6(2.4)$ & \\
\hline \multirow{4}{*}{2} & \multirow{4}{*}{$\begin{array}{l}\text { Getting dressed or } \\
\text { undressed }\end{array}$} & \multirow{2}{*}{$\mathrm{OH} 1$} & Yes & $42(65.6)$ & $14(21.9)$ & $7(10.9)$ & $1(1.6)$ & \multirow{2}{*}{0.865} \\
\hline & & & No & $175(70)$ & $52(20.8)$ & $20(8)$ & $3(1.2)$ & \\
\hline & & \multirow{2}{*}{$\mathrm{OH} 3$} & Yes & $34(51.5)$ & $18(27.3)$ & $12(18.2)$ & $2(3)$ & \multirow{2}{*}{0.001} \\
\hline & & & No & $183(73.8)$ & $48(19.4)$ & $15(6)$ & $2(0.8)$ & \\
\hline \multirow{4}{*}{3} & \multirow{4}{*}{ Preparing simple meals } & \multirow{2}{*}{$\mathrm{OH} 1$} & Yes & $35(54.7)$ & $23(35.9)$ & $5(7.8)$ & $1(1.6)$ & \multirow{2}{*}{0.86} \\
\hline & & & No & $170(68)$ & $52(20.8)$ & $21(8.4)$ & $7(2.8)$ & \\
\hline & & \multirow{2}{*}{$\mathrm{OH} 3$} & Yes & $30(45.5)$ & $22(33.3)$ & $12(18.2)$ & $2(3)$ & \multirow{2}{*}{$<0.001$} \\
\hline & & & No & $175(70.6)$ & $53(21.4)$ & $14(5.6)$ & $6(2.4)$ & \\
\hline \multirow{4}{*}{4} & \multirow{4}{*}{ Taking a bath or shower } & $\mathrm{OH} 1$ & Yes & $32(50)$ & $15(23.4)$ & $12(18.8)$ & $5(7.8)$ & 0540 \\
\hline & & ОНІ & No & $136(54.4)$ & $68(27.2)$ & $32(12.8)$ & $14(5.6)$ & 0.540 \\
\hline & & & Yes & $26(39.4)$ & $19(28.8)$ & $14(21.2)$ & $7(10.6)$ & 0026 \\
\hline & & OH3 & No & 142 & 57.3 & $64(25.8)$ & $30(12.1)$ & 0.026 \\
\hline & & $\mathrm{OH} 1$ & Yes & $31(48.4)$ & $22(34.4)$ & $8(12.5)$ & $3(4.7)$ & 0007 \\
\hline 5 & Going to the shon & $\mathrm{OHI}$ & No & $162(64.8)$ & $61(24.4)$ & $22(8.8)$ & $5(2)$ & 0.097 \\
\hline & & & Yes & $32(48.5)$ & $21(31.8)$ & $9(13.6)$ & $4(6.1)$ & 0033 \\
\hline & & $\mathrm{OH} 3$ & No & $161(64.9)$ & $62(25)$ & $21(8.5)$ & $4(1.6)$ & 0.033 \\
\hline & & $\mathrm{OH} 1$ & Yes & $9(32.1)$ & $15(53.6)$ & $4(14.3)$ & - & 0545 \\
\hline 6 & Getting in or out of a & $\mathrm{OHI}$ & No & $150(52.4)$ & $103(36)$ & $28(9.8)$ & $5(1.7)$ & 0.545 \\
\hline 0 & chair & $\mathrm{OH}_{3}$ & Yes & $25(37.9)$ & $30(45.5)$ & $10(15.2)$ & $1(1.5)$ & 0108 \\
\hline & & $\mathrm{OH} 3$ & No & $134(54)$ & $88(35.5)$ & $22(8.9)$ & $4(1.6)$ & 0.108 \\
\hline & & & Yes & $21(32.8)$ & $23(35.9)$ & $16(25)$ & $4(6.3)$ & \\
\hline 7 & Going un or down ctairc & $\mathrm{OHI}$ & No & $79(31.6)$ & $97(38.8)$ & $63(25.2)$ & $11(4.4)$ & 0.919 \\
\hline 1 & Joing up or cown stalls & & Yes & $19(28.8)$ & $20(30.3)$ & $22(33.3)$ & $5(7.6)$ & \\
\hline & & $\mathrm{OH} 3$ & No & $81(32.7)$ & $100(40.3)$ & $57(23)$ & $10(4)$ & 0.157 \\
\hline & & & Yes & $28(43.8)$ & $28(43.8)$ & $5(7.8)$ & $3(4.7)$ & \\
\hline 8 & Walking around in the & $\mathrm{OHI}$ & No & $147(58.8)$ & $70(28)$ & $31(12.4)$ & $2(0.8)$ & 0.008 \\
\hline 0 & neighbourhood & & Yes & $26(39.4)$ & $24(36.4)$ & $14(21.2)$ & $2(3)$ & \\
\hline & & OH3 & No & $149(60.1)$ & $74(29.8)$ & $22(8.9)$ & $3(1.2)$ & 0.005 \\
\hline & & & Yes & $26(40.6)$ & $17(26.6)$ & $17(26.6)$ & $4(6.3)$ & \\
\hline 0 & Reaching for something & $\mathrm{OHI}$ & No & $159(63.6)$ & $45(18)$ & $36(14.4)$ & $10(4)$ & 0.009 \\
\hline 9 & above your head or on & & Yes & $25(37.9)$ & $21(31.8)$ & $15(22.7)$ & $5(7.6)$ & \\
\hline & & $\mathrm{OH} 3$ & No & $160(64.5)$ & $41(16.5)$ & $38(15.3)$ & $9(3.6)$ & 0.001 \\
\hline & & & Yes & $25(39.1)$ & $29(45.3)$ & $9(14.1)$ & $1(1.6)$ & 0265 \\
\hline 10 & Going to answer the & $\mathrm{OHI}$ & No & $128(51.2)$ & $82(32.8)$ & $34(13.6)$ & $6(2.4)$ & 0.263 \\
\hline 10 & $\begin{array}{l}\text { telephone berore it stops } \\
\text { ringing }\end{array}$ & & Yes & $21(31.8)$ & $28(42.4)$ & $16(24.2)$ & $1(1.5)$ & \\
\hline & & OH3 & No & $132(53.2)$ & $83(33.5)$ & $27(10.9)$ & $6(2.4)$ & 0.004 \\
\hline & & $\mathrm{OH} 1$ & Yes & $16(25)$ & $16(25)$ & $25(39.1)$ & $7(10.9)$ & \\
\hline 11 & Walking on a slippery & $O H 1$ & No & $152(60.8)$ & $23(9.2)$ & $55(22)$ & $20(8)$ & $<0.001$ \\
\hline & surface (e.g. wet or icy) & $\mathrm{OH}_{3}+2 \mathrm{C}$ & Yes & $16(24.2)$ & $13(19.7)$ & $24(36.4)$ & $13(19.7)$ & \\
\hline & & UIIJ & No & $152(61.3)$ & $26(10.5)$ & $56(22.6)$ & $14(5.6)$ & \\
\hline
\end{tabular}




\begin{tabular}{|c|c|c|c|c|c|c|c|c|}
\hline \multirow{4}{*}{12} & \multirow{4}{*}{$\begin{array}{l}\text { Visiting a friend or } \\
\text { relative }\end{array}$} & \multirow{2}{*}{$\mathrm{OH} 1$} & Yes & $27(42.2)$ & $27(42.2)$ & $9(14.1)$ & $1(1.6)$ & \multirow{2}{*}{0.048} \\
\hline & & & No & $153(61.2)$ & $67(26.8)$ & $28(11.2)$ & $2(0.8)$ & \\
\hline & & \multirow{2}{*}{$\mathrm{OH} 3$} & Yes & $26(39.4)$ & $22(33.3)$ & $15(22.7)$ & $3(4.5)$ & \multirow{2}{*}{$<0.001$} \\
\hline & & & No & $154(62.1)$ & $72(29)$ & $22(8.9)$ & - & \\
\hline \multirow{4}{*}{13} & \multirow{4}{*}{$\begin{array}{l}\text { Walking in a place with } \\
\text { crowds }\end{array}$} & \multirow{2}{*}{$\mathrm{OH} 1$} & Yes & $18(28.1)$ & $28(43.8)$ & $16(25)$ & $2(3.1)$ & \multirow{2}{*}{0.308} \\
\hline & & & No & $99(39.6)$ & $82(32.8)$ & $60(24)$ & $9(3.6)$ & \\
\hline & & \multirow{2}{*}{$\mathrm{OH} 3$} & Yes & $16(24.2)$ & $24(36.4)$ & $21(31.8)$ & $5(7.6)$ & \multirow{2}{*}{0.02} \\
\hline & & & No & $101(40.7)$ & $86(34.7)$ & $55(22.2)$ & $6(2.4)$ & \\
\hline \multirow{4}{*}{14} & \multirow{4}{*}{$\begin{array}{l}\text { Walking on an uneven } \\
\text { surface (e.g. rocky } \\
\text { ground. poorly } \\
\text { maintained pavement) }\end{array}$} & \multirow{2}{*}{$\mathrm{OH} 1$} & Yes & $16(25)$ & $19(29.7)$ & $25(39.1)$ & $4(6.3)$ & \multirow{2}{*}{$<0.001$} \\
\hline & & & No & $150(60)$ & 34 (13.6) & 54 (21.6) & $12(4.8)$ & \\
\hline & & \multirow{2}{*}{$\mathrm{OH} 3$} & Yes & $17(25.8)$ & $16(24.2)$ & $25(37.9)$ & $8(12.1)$ & \multirow{2}{*}{$<0.001$} \\
\hline & & & No & $149(60.1)$ & $37(14.9)$ & $54(21.8)$ & $8(3.2)$ & \\
\hline \multirow{4}{*}{15} & \multirow{4}{*}{$\begin{array}{l}\text { Walking up or down a } \\
\text { slope }\end{array}$} & \multirow{2}{*}{$\mathrm{OH} 1$} & Yes & $12(18.8)$ & $28(43.8)$ & $20(31.3)$ & $4(6.3)$ & \multirow{2}{*}{0.376} \\
\hline & & & No & $63(25.3)$ & $119(47.8)$ & $57(22.9)$ & $10(4)$ & \\
\hline & & \multirow{2}{*}{$\mathrm{OH} 3$} & Yes & $10(15.2)$ & $27(40.9)$ & $23(34.8)$ & $6(9.1)$ & \multirow{2}{*}{0.012} \\
\hline & & & No & $65(26.3)$ & $120(48.6)$ & 54 (21.9) & $8(3.2)$ & \\
\hline \multirow{4}{*}{16} & \multirow{4}{*}{$\begin{array}{l}\text { Going out to a social } \\
\text { event (e.g. religious } \\
\text { service. family gathering } \\
\text { or club meeting) }\end{array}$} & \multirow{2}{*}{$\mathrm{OH} 1$} & Yes & $24(37.5)$ & $23(35.9)$ & $16(25)$ & $1(1.6)$ & \multirow{2}{*}{0.001} \\
\hline & & & No & $158(63.2)$ & $48(19.2)$ & 37 (14.8) & $7(2.8)$ & \\
\hline & & \multirow{2}{*}{$\mathrm{OH} 3$} & Yes & $25(37.9)$ & $20(30.3)$ & $17(25.8)$ & $4(6.1)$ & \multirow{2}{*}{0.001} \\
\hline & & & No & $157(63.3)$ & $51(20.6)$ & $36(14.5)$ & $4(1.6)$ & \\
\hline
\end{tabular}

OH1: orthostatic hypotension, first minute measurement, $\mathrm{OH} 3$ : orthostatic hypotension, third minute measurement. The data is expressed using $\mathrm{n}(\%)$. 